\title{
Erotic Exuberance: Bataille's Notion of Eroticism
}

\author{
Thomas Minguy
}

Eroticism, it may be said, is assenting to life up to the point of death. (Bataille, Erotism 11)

The figure of Eros in philosophy often relates to a notion of the beyond: a desire of the ineffable, or a desire of what lies beyond reality. Opposed to other forms of love, it is not the desire for a communication and a shared relationship. It is neither a free-giving love: it appears to be the desire of a selfhood that wants to be satisfied. Eros is thus the quest for filling oneself with what will bring delight. The philosophical Eros presented in Plato's Symposium follows that logic: a desire for a satisfaction in the vision-and almost possession - of the beautiful forms, and in the end of the Beautiful as such. Eros is egotistic and self-interested; the desire for possessing the desirable, and then throwing it away when it does not satisfy anymore. In that sense, it is the impossible desire for being filled by ecstasy. The Platonic Eros seeks the desirable in what is external to the desiring subject, and thus it seeks to bring this beyond in the hands of the desiring one. "The loved one should be mine," says the erotic person. Even Aristophanes' speech aims at a possession of the loved one within the constitution of a complete self: the two lovers united in the hermaphrodite form are satisfied. They do not desire the beyond anymore, because the desirable is within them.

This vision leads to the possibility of eroticism, which is the sexual way to embody Eros. It is the quest for the ultimate pleasure through extreme experiences. A desire to lose oneself in pleasure in a way that pleasure takes over. The search for a pleasure beyond conventional sexual behaviours: it is not love, but self-interested desire for pleasure. Eroticism as a form of Eros thus appears to be the embodied quest for the ineffable object of desire. A subject throwing herself in a world of sensual pleasure that will never totally satisfy her.

For the French philosopher Georges Bataille, this conception of eroticism, and thus of Eros, does not look in the right direction: Eros is not to be understood according to the logic of selfish desire, but under the loss of selfhood-which is akin to the experience of death. Eroticism is indeed 
an extreme experience, but that cannot be conceived as a quest for satisfaction or possession. The extreme exuberance-and even-of the erotic desire does not fit in a world ruled by rational principles, and this is why when under the rapture of erotic desires, we lose our minds, and ourselves in the moment. For Bataille, this loss of rationality-this loss of seriousness - corresponds to the truth of Eros. Or at least to what Eros really is for us, human beings. It is loss: of our seriousness, our stability, our rationality - almost of our humanity. Even though, Bataille associates eroticism with the experience of existence as its fullest: it is the attainment of sovereignty through transgressive evil. "In that he is an erotic animal, man is a problem for himself. Eroticism is the problematic part of ourselves. ... I believe that the supreme philosophical question coincides with the summits of eroticism." (Bataille, Erotism 273) Eros, in that case, is not a mere manifestation of love, but something that should appear as opening the possibility to understand human life even deeper. The study of Eros is not the study of desire, but the study of the truth of human existence, of the possibility sovereign freedom. If Bataille claims that philosophy ultimate question corresponds with eroticism, we need to see how eroticism is not only mere selfish desire, but something deeper; we need to see how the exuberance of erotic desire is part of what it means to be human.

\section{Twofold realms: Continuity and Discontinuity}

The possibility of eroticism, and so of the experience of Eros, comes from the structure of existence. According to Bataille, life is divided in two realms: the continuous existence and the discontinuous one. Eros is a phenomenon that happens in the realm of continuous existence, but depends on the fact that beings experiencing erotic love live within the discontinuous existence. In other words, eroticism is the disturbance of the discontinuous existence that brings discontinuous beings into continuous existence. From the outset, we can see that eroticism is a transgressionwhich will become associated with evil later.

Discontinuous existence is the realm of isolated beings. In it, entities are limited, and thus have a selfhood, even a sense of seriousness. Continuous existence, on the other hand, is the realm in which the Self is no more, in which energies are ever moving and stability is impossible. The realm of animality; a night in which separated forms and beings are not, but in which everything is part of a continuity. Eroticism is thus the transgression of the determined limits of discontinuous beings in order to experience the violence of continuity. In order to understand this, we need to understand the structure of each form of existence that Bataille describes, and only through a thorough understanding of these structures 
can we see how they create the possibility of erotic experiences - and what this phenomenon entails.

Continuous existence is not a primitive state, but a chaotic one, in which stability and rest are not possible. It is a state of movement and continuity, closer to what we can call the elemental than to the world of distinct shapes and beings. According to Bataille, existence is movement, in the sense that it is a flux of energies that moves around the Earth without purpose. As such, it is a wasteful process, and expenditure without end. The movement of life is a movement of expenditure. It is energetic and exuberant, because it is a play of forces that strive to affirm themselves through the overcoming of lesser manifestations. The grass grows out of the solar energies, the fawn grows out of the grass, the wolf feeds on the accumulated forces of the fawn's, and so on. Overall, each new level is a more exuberant display of energies, and each new level asks for more and more forces to be in play (see Bataille, Part maudite). The wolf needs to use more energy to hunt the fawn than the grass to accumulate the energies of the sun to grow. This continuity entails what Bataille calls a general economy, one that is not grounded in principle of accumulation, but on expenditure. In continuity nothing is accumulated or loss: on the global scale-the general one-the energy circulates endlessly, without purpose. From the perspective of the singular and isolated entities, it is a movement of expenditure that overcomes and destroys them. From the perspective of continuity, it is existence at its fullest. The continuous existence is the one in which life is immanentand seen as such. For the predator, the prey is only a source of energy, not an isolated being apart from it. It is a unique manifestation, in the sense that the fawn is a concentrated amount of energies with a given shape and in a given spatiotemporal position, but for any entity in continuity, the fawn partakes in the same movement of expenditure we call life.

We should consider continuous existence as a plane of immanence, a plane on which life manifests itself through level of intensity that are in communication with each other. In Bataille's terminology, beings are to be considered according to the amount of energy they represent; beings are exuberant, because that is the way in which they can affirm themselves; expenditure as the logic of continuous existence. ${ }^{1}$ As we hinted at earlier, expenditure is only one from the perspective of isolated and discontinuous beings. We see continuous existence-and existence as such - as a movement of expenditure because we are used to think under the logic of preservation, that is through the assumption that life is the life of the self.

${ }^{1}$ We will draw a lot for this distinction between general and restrained economy on Bataille's most systematic work: La part maudite. We recommend - obviously— to read the whole work, since it is a thorough analysis of economy through history. It seems, however, that the reader could find the essence of our explanation in the first part, Introduction théorique (25-46). 
Under that vision, which Bataille calls restrained economy, energies are to be accumulated for a purpose. Discontinuous beings calculate in order to remain in their finitude. The surplus of energies are used either as an augmentation of one's comfort, or as investment in new forms of accumulation. The surplus is thus always an accursed share, because it is a remainder - and a reminder - of the fact that life is overflowing, and not to be contained within limited existences. Life, however, does not take into consideration the desire of preservation. Its movement-violent and exuberant - is unstoppable, and refuse to be contained in a single place. This is why the general economy, the one that looks at continuity and beyond the desire of preservation of the discontinuous entity, appears as a movement of expenditure: it is pointless, without any form of calculus, and most of all without any possibility of accumulation.

The discontinuous existence creates the possibility for stability. It is the realm in which the self wants to survive and be a center of meaning. It is the world of human rationality and existence. As such, it is built around the logic of restrained economy, one that only aims at the preservation of limited selves. If from the economic standpoint, it refuses expenditure, the same will go morally. The surplus to spend is accursed, excess is evil. In other words, in the desire for preservation comes with a distinction between good and evil-good being the preservation of the self and evil its destruction. "In popular opinion [jugement vulgaire], the substantive aspect of moral action is its subordination to utility, and the impulses for a yearning to transcend [dépasser] being are related to the good of one's being." (Bataille, Nietzsche 29) Morality is always a desire to go beyond our limits. The categorical imperative-probably the extreme of moral desire - is universal, beyond our reach, and dictating us how to act from on high. This, however, as any moral that finds its purpose within a restrained economy, only aims at the preservation of the self. According to Bataille, it is thus a fallen morality. The true moral impulse-what he phrases "morale du sommet" is not aimed at preservation, but at communication, that is to say, at continuity. In other words, the morale $d u$ sommet is transgressive of the self, but most of all evil. "All 'communication' participates in suicide, in crime. ... By destroying the integrity of existence in myself and in others, I open myself to communion-I attain a moral summit." (26) With restrained economy comes the morality that establishes good as the good of a limited being. In both cases, the goal is to restrain the chaotic energies in order to accumulate and calculate. It is a rejection of expenditure. Taboos and moral rules will always do violence to the continuous movement of expenditure. Expenditure is considered violent and evil, because it is without purpose, but Bataille stresses out how taboos and restrictions are other ways to justify our own inner violence - that we have because life as such is violent. "If my life is threatened for some comprehensible goodfor instance, for the nation of a useful cause - my behavior is deserving 
and is popularly considered moral. And for the same reasons I'll kill and wreck havoc in conformity to moral law. I another area, squandering resources through gambling and drinking is wrong: though it's right to improve the fate of the poor." (28) The morality that comes with discontinuous existence is an attempt to give a purpose to expenditure and the movement of energies: it tries to restrain by making calculable. As long as we conceive existence as taking place within the restrained economy, good will always be related to a form of preservation, whereas evil will be a wasteful movement of expenditure.

The difference, according to Bataille, between animals and human beings is in their relation to the world, in the sense that only human beings place themselves in a discontinuous existence, and as such only human beings embrace seriousness and the possibility of meaning. Human beings create meaning: in their serious relation with their environment and their world, they strive to master the exuberant energies to create something stable and meaningful. In that sense, human existence is paradoxical, in the sense that it is the use of immanent energies in order to crystallize them, and bring them out of immanence: it is the creative impulse that seeks to stop itself in a masterpiece. "In a word they [human beings] distinguished themselves from the animals by work." (Erotism 30) Something is meaningful if it has stability, if it becomes like a gravitational center that draws other objects towards it. Such a thing is impossible in the continuous existence, since there is no center but only a movement of forces. Working meaning means creating centers of gravity, figures or seriousness: faces that are stable and authoritative. Seriousness is a state characteristic of discontinuous existence, because it asks for the stability of a given selfhood. It asks for maintaining stable one's face and state. It is a striving for an autonomous existence - an autonomous self.

It isn't as a definite thing that humanity runs into conflict with nature (and it's likewise not as a definite thing that nature is against humanity). Humanity's is the effort to be autonomous. ... In principle nature appears as confused: human existence is what is tempted to remove itself from the confusion, to reduce itself to the purity of rational principles. (Guilty 129)

The discontinuous existence is one opposed to chaos and disorder: it is the realm of authority and hierarchy, the place where it is possible to be a determining center, a self and a consciousness. It is the life of a being that looks at life at distance — as form on high.

This opposition between continuity and discontinuity constitutes what it means to be human according to Bataille: it is the contrast between what some could call our animal and our rational side. Such an interpretation, however, would reduce Bataille's thought: continuity is not a primitive realm that we go back to. It is always there, in the background 
of the discontinuous existence. The forces that allow human beings to create stability, authority and meaning are the exuberant forces of existence. The purity of rational principles which humanity seeks to attain is only attainable through a display of forces that seeks to eradicates chaos: it is violence that seeks to overcome its own violent truth.

Man has built up the rational world by his own efforts, but there remains within him an undercurrent of violence. Nature herself is violent, and however reasonable we may grow we may be mastered anew by a violence no longer that of nature but that of a rational being who tries to obey but who succumbs to stirring within himself which he cannot bring to heel. (Erotism 40)

This is where the erotic makes its appearance. We already hinted at the fact that eroticism is the transgression of discontinuous existence so human beings can go back to a state of continuity. We should then see how eroticism is related to Bataillean communication, which is, as we saw, a form of evil. Even further: it is the possibility of human sovereignty. By that term, we need to understand not a state of mastery, but an escape from the logic of mastery and work. Sovereignty, in Bataille's philosophy, is deeply evil, because it is a transgression of what limits and constrains us. Eroticism differs from sexuality in the sense that through a desire for communication, the lovers are not driven by a logic of satisfaction-which would preserve their selves-but on a logic of continuity. This is a tension in Bataille's thought since it still seems that such a desire would ask for a form of calculation and thus would fall under the logic of restrained economy. What is truly at stake here, however, is to understand the relation between eroticism and evil, leading us to sovereignty, and its distinction from mere sexuality, which is oriented towards the future hope for satisfaction.

Seriousness is the state of being in which there is stability and the possibility of preservation: it is the "end" of violence and exuberance. The serious self can consider herself as the subject that look objectively at the world. It is the self that refuses to be thrown into existence, but that strives to master and work within it - through physical or intellectual means. The serious existence entailed by work comes with a projective mode of existence, and thus with a linear temporality. The self from the past, the one in the present and the one of the future are all the same selfhood that develops itself, but stays within a limited existence. In the violence of transgression - or of communication, what appears is the fact that life is a play of energies, a play that cannot allow seriousness. What appears is the plane of immanence, that is a plane that does not allow projects, but an intense immersion in expenditure. It is an experience of existence as such, i.e. a pure experience of what it means to be. Seriousness is thus necessarily anxious, because, as Bataille says it, the serious and working self of discontinuous existence is always conscious of a violence that still 
lingers within life as such, a violence that could bring projects, hopes and dreams to naught; a violence that could disturb the calm atmosphere of a stable life. In the creative impulses of work, what appears is the destructive possibility of creativity; and in the violence of passions and desires what appear is the dissolution of a selfhood, and the loss of seriousness.

Eros appears in Bataillean thought to be the possibility of a being that wants to overflow, and to breaks out of the restricted seriousness. It is the explosion of selfhood. Eroticism is the "fall" of the working and serious self into the continuous and exuberant communication. In a certain sense, eroticism is an attempt to be in a state of innocence: a state in which the serious self is not anxious nor at stake with a world that must remain stable, but in a state where the self is destroyed and in continuity with the loved one.

Isolate being is a deception (which reflects the crowd's distress by reversing it), and the couple, becoming stable at last, is a negation of love. But what goes from one lover to the other is a movement that puts an end to isolation or at least makes it waver. Isolate being is risked, opens to what's beyond itself, to what's beyond the couple even -monstrous excess. (Guilty 158)

The logic of Eros is thus the breaking apart of the stable and serious existence, and the embrace of continuous existence. It is the death of the isolated self and the birth of a communication that does not take place in a discontinuous world. It is the transgression of the limits that are necessary to the stable and serious existence, and thus it is an aspect of human existence that is utterly exuberant and non-rational, in the sense that it cannot be understood under the logic of work and seriousness. Eroticism is an experience of life in all its intensity and exuberance: it is the death of the isolated self that suddenly finds itself in the midst of life's orgy, that is in the midst of the play of energies that existence is. Death, here, is not a biological ending of function, but the movement that breaks the limited existence. Death is the experience of the beyond the limits - an experience of the impossible. "A request you ought to make to your boyfriend or girlfriend: be the victim of the impossible." (40) Far from being the desire to own the other, what erotic love craves is the experience of the impossible, that is the experience of existence in its violence and exuberance, where possibility, as in the logic of seriousness, is impossible. This is equivalent to death, since it is, in a way, an experience of nothingness. Serious existence dwells within the possible, that is within the possibility to calculate and use entities within a desire for preservation. What is deemed impossible is what escape that logic, so in a sense everything that will be labeled evil, wasteful and announcing death. We already saw that Bataille, in On Nietzsche, says that "squandering" and "drinking" are reprehensible, whereas killing in the name of a greater good 
is deemed good: in the former case, it is because it leads nowhere and is a form of loss and perdition; in the latter there is a certain calculation and a purpose. Eroticism opposes sexuality in the same way: the former is wasteful, without purpose and transgressive of selfhood; the latter is a craving for being filled with pleasure.

Such a logic then takes part into the movement of transgression and death, in the sense that what is sought is the transgression of limits, and thus the death of selfhood. Escaping the possibility of satisfaction and embracing the excess of energies; sacrificing the limited selfhood to find the continuity of existence.

\section{Transgression and Death}

In the dichotomy between continuous and discontinuous existence, what is at play is the stability of self-consciousness, and thus of selfhood. Philosophical tradition often considered the problem of subjectivityobjectivity through the lenses of a dichotomy between the subject and the external world in which it is thrown. It is the easiest way to conceive discontinuous existence, because if the subject is separated from the objects, there is no continuity but a world made of specific entities that only a separated and isolated self can know. Cartesian thought creates that dichotomy, as Descartes tries to escape the blurred senses to understand the world in clear and distinct ideas. This is even his criteria of truth: clarity and distinction. With Hegel, and subsequent developments in phenomenology, what appears is that the subjective must collapse with the objective, and thus the philosophical analysis of the development of selfconsciousness becomes the main task of philosophy. This task is, according to Bataille, the creation of a solidified self that is enclosed within determinate limits. In Levinas' vocabulary, philosophy of such a tradition creates a totality that cuts itself from the infinite, in the sense that self-consciousness as subject and object of itself can only look at the universe as something limited-that can expand through Hegelian dialectic, for example, but that remains ultimately limited, i.e. looking at itself. Discontinuous existence, as we saw, is exactly that: the creation of a limited self that can only look at other objects through a limited vision. Quiddity, essence, categories: all of these are way to maintain the world within a limited self-consciousness. Immanence and continuous energies must be shaped to become meaningful-e.g. the overcoming of sense certainty is the beginning of Hegelian development of self-consciousness, which leads to World Spirit, the ultimate expression of a universal selfconsciousness, the ultimate totality.

Disturbances of discontinuous existence are moments in which the seriousness of the stable selfhood is broken. Eroticism is such a disturbance. What appears in eroticism is the vision that the limited self is 
not everything, and that it is a manifestation of energies - chaotic and exuberant energies. In the shattering of the self, what is visible is the flux of energies, the exuberance of living beings. Being in continuity does not mean being lost without any possibility of differentiation. It means seeing the world as made up of energies, and ourselves being a unique manifestation of energies.

Your business is questing for an unknowable destiny. Because of this you'll have to struggle by hating limits-limits which the system of respectability sets up against freedom. On account of this, you'll need to arm yourself with secret pride and indomitable willpower. The advantages given to you by chance-your beauty, glamour, and the untamed impulsiveness of your life-are required for your laceration. (Guilty 161)

The uniqueness of the loved one is ephemeral, and its only truth is its oncoming death. The limits, Bataille says, are there to be overcome and destroyed, because as limits they contain the energies that we are. The loved one, with her unique beauty, arouse our lust and desire: we desire this unique manifestation of energy. We desire to unleash the energies that are hidden under the veil of a limited self - under the veil or her unique selfhood. "Eroticism is not satisfied in contentment; it is the release of excess forces, craving extreme experiences in extreme torments and extreme pleasures." (Lingis, Dangerous 141) In that sense, eroticism is a transgressive movement: the transgression of selfhood in a desire to unleash energies. This unleashing is communication, in the sense that through the transgression of limits we gain access to what is utterly inaccessible to limited selves. Through an experience akin to death-in an experience that goes beyond limits-we experience continuous existence, in which every entity is in communication with others. It is an extreme movement that seeks to make visible the energies of the world and the excessive movement of life.

The serious self stands proud above the ground, and it keeps a physical image that seems solid and organized. It is the body of an organism, something with a hierarchy and an organisation that makes sense (see Deleuze \& Guattari). The hands are there to hold and shape, the head to think and see, the mouth to talk and all together the brain controls the movement of our bodies with purposes. Through erotic impulses such a vision is shattered. In the erotic moment, what is sought is expenditurefree expenditure of excessive energies that are not related to any notion of utility. "An erotic object functions as the open gate toward which the shock waves of our energies rush to be compressed and intensified and inflamed there, and to break forth into the dazzling darkness beyond." (Lingis, Dangerous 143) Eros is thus not a desire to possess, but to unleash. The object of erotic desire thus becomes a site of transgression: it is the sacrifice of its usefulness. In other words, eroticism is the movement 
in which what has the character of seriousness is brought down in obscenity. This is on this basis that it differentiates itself from mere sexuality.

Sexuality is always linked with a transgression of selfhood, in the fact that reproduction of two separated beings asks for their oncoming death. "The parents survive the birth of their offspring but the reprieve is only temporary. ... Death follows reproduction with sexual beings too, at a distance even if not immediately." (Bataille, Erotism 100-1) Thus, reproduction is a transgression of selfhood, in the sense that it is the vision of the future death of the parents: it is the annunciation of the end of a limited being through the apparition of another limited being. Even more so, sexuality, in a physical sense, is a transgression of one's body. Through sensual caresses and different penetrations, one's body is transgressed. With

sexuality particularly a sense of the existence o the others beyond the self-feeling suggests a possible continuity as opposed to the original discontinuity. Other individuals, in sexuality, are continually putting forward the possibility of continuity; others are continually threatening a rent in the seamless garment of separate individuality. (102)

Through penetration and sexual acts, the self of the other is no more separated, but enters into a physical continuity. Even then, there is a futural aspect in sexuality, and even more a logic of satisfaction it the structure of desire. One can look at how Freud, in Three Essays on the Theory of Sexuality will subsume sexual drives under the pleasure principle. Drives create erogenous zones under a logic of lack and satisfaction: "The sexual aim of the infantile drive consists in obtaining satisfaction by means of an appropriate stimulation of the erogenous zone that has been selected in one way or the other." (Freud, Three Essays 45) Under that logic, sexuality-and sexual desire that is too often taken as Eros - is always seeking to fill a hole (often quite literally) in the limited self. Sexuality is thus always a calculative process of lack, satisfaction and pleasure.

Eroticism is different, in the sense that Eros is a desire for continuity, for exceeding limits and overflowing.

The sensual touch becomes erotic when there is violation of the person of another. There is a breaking down of someone's public and decent presence and functioning in the ordered and regulated roles of the social field. There is a specific excitement in the collapse of posture and wariness, the divestment of functions, roles, and selfrespect. (Lingis, Violence 82) 
Eros is not the desires for satisfaction of the self, but for the breaking apart of limits. Eros is the desire to lose oneself in the chaotic energies of life. "The physical urge is curiously foreign to human life, loosed without reference to it so long as it remains silent and keeps away. The being yielding to that urge is human no longer but, like the beasts, a prey of blind forces in action, wallowing in blindness and oblivion." (Bataille, Erotism 105) Erotic pleasure is the liberation of the violence that lingers in human beings, the violence of life that is repressed and crystallized in seriousness through taboos and moral restrictions. Christian religion, for example, condemn Eros and prefers Philia, and by far Agape. Eros is considered as a possessive and egotistic desire, where Agape is free giving; but for Bataille Eros corresponds with a lost of the self, and so it cannot be egotistic. It is indeed related to the uniqueness of a selfhood, but only to break that selfhood.

To those who avidly desire laceration, individuality is necessary. Laceration wouldn't be itself if not a laceration of a particular person, a person chosen for his or her plentitude. Excess life, fullness, are a means of highlighting the void, and this fullness and this excess are that person's to the extent that they dissolve us, taking away the safety rail that separates us from the void. (Guilty 157)

The fact that this unique being, in its given beauty and uniqueness is a unique manifestation of life makes even more explicit the aspect of chance and absurdity that rules our existences: it makes explicit the constant movement of energies around the Earth that are chaotic and nonlogical. The uniqueness of the lover shows that it is impossible to possess such a being, because the life of such a unique person is an ephemeral manifestation in an energetic life. And this life will kill her. When Bataille talks about this "torn" aspect of limited beings, he means that our discontinuous life always comes with the sense of a continuity that we strive to escape: we tear ourselves out of the continuous existence. In eroticism, what happens is that we seek the place where we were torn apart, and we connect through these open wounds. "When love denies limited existences, it gives them in return an infinity of emptiness. It limits them to waiting for what they are not." (154) Erotic love is the negation of limits, the transgression of seriousness and the openness to the emptiness of what lies beyond our limits: the emptiness of a meaningless chaos of energies.

Eroticism thus escapes the logic of truth. Truth can only appear-or be understood - in a world where it is possible to stabilize objects and to look at them. Even in the possibility of a fluid truth, as in Hegelian dialectic, truth depends on the certain stability of a given stage of the dialectic. "The True is thus the Bacchanalian revel in which no member is not drunk; yet because each member collapses as soon as he drops out, the 
revel is just as much transparent and simple repose." (Hegel 27) With such an account, what appears is that truth is fluid and changes over time, but the members of the bacchanalian revel collapses, and the "transparent and simple repose" is the vision of its development over time, and thus the possibility of grasping truth.

In erotic contact, the coherent lines of discourse break up into teasing, nonsense, and laughter. Erotic contact disconnects from the rational language that seeks to establish truth, that is, what is true for everyone; erotic utterances are a private language. Nothing is to be learned from listening in to lover's talk. (Lingis, Violence 84)

There is no purpose in the erotic pleasure, because what is sought is not satisfaction nor reproduction, but loss and abandonment. It is, as we said earlier, giving oneself to the violence of life, and embracing the chaotic movements of energies that are around the globe. It is leaving the inertia of a serious life and embracing the high velocity of energies circling the world. As such, eroticism thus leaves the realm in which truth is possible to understand, and seeks to experience the truth of existence, i.e. its violence and exuberance. Leaving the logic of understanding (of grasping the truth), it enters logic of immanence, in which truth is not seized, but created and experienced.

Through eroticism, what appears is the breakdown of seriousness and the openness to the death of limitations. When there are no limits, objects are no more graspable: they become fluid and their truth is no more something we can hold, but that we must create with. When we kiss the lips of our lovers, these lips cannot do their role: they cannot eat nor talk, they can only enrapture us in this excess of energies. Same when we make love to our lovers: in the taking away of the clothes of the other, what appears is the frailty and vulnerability of a body that is no more able to walk proudly on Earth. In the erotic activity we lose control over our limbs and we collapse in numerous ecstasies that cannot be associated with utility, and in a certain sense we die in the arms of our lover, because we are no more this serious self that was limited. We embrace what lies beyond the limits of our selves, and such a limit is beyond the grasp of our reason, because it is nonsensical.

The caressing hands move aimlessly over the flesh in random, repetitious movements. The muscles tighten, harden, the limbs grope and grapple, pistons and rods of a machine that has no idea what it is trying to achieve. The it collapses, gelatinizes, melts, runs. The trapped blood surges and pounds, the heat billows, the spirit vaporizes in gasps and sighs. In dissolute ecstasy the body that has become ligneous, ferric, coral now curdles, dissolves, liquefies, vaporizes, becomes radioactive, solar, nocturnal. (Lingis, Dangerous 148) 
The body loses its posture as the mind loses its grip over the world. Eroticism is when we embrace life in its fullest manifestation, through the continuity with an other. It is as simple as in Bataille's Histoire de l'oeil, in which one of the first erotic moment is when a young girl sits in a plate, because she says that plates exist so we can sit in them. ${ }^{2}$ In this ridiculous breaking of seriousness and stability, the young boy experiences an orgasm that happens only because the plate is no more a plate, but suddenly an gate to the excessive energies of the world. Breaking the serious stability of the plate is childish, and laughable - and hardly erotic for many people; but what is the difference between this and the crossdressing or even sexual activities in which the mouth it no more used to eat or talk, but to suck, swallow, bite, moan, laugh, and scream? The costume of the erotic partner is only there to be taken out of the realm of objects, and to be sacrificed on the altar of laughter. The transgression of eroticism is not only a breaking of a taboo: it is rendering what is deemed serious obscene. In Bataille's erotica, the movement is not one of mere sexuality in which individuals are copulating for the sake of pleasure. The transgression is a transformation of what is deemed serious and useful into something laughable and devoid of any use. It is an embrace of evilness. This also explains Bataille's fascination for writers who are fascinated with evil as an experience of freedom: Brontë, Blake, Sade, Baudelaire, Genet, etc. Eroticism differs from sexuality in the absence of purpose, but mostly in the reversal of values, the unleashing of energies that are covered by calculative reasoning and the logic of lack and satisfaction.

The zone of decomposition of the world of work and reason, this zone of blood and semen and vaginal secretions, of excremental discharges and corpses, this zone too of mushrooming eddies of nameless inhuman life, which fills us with exultant anguish and anguished exultation, is the zone of the sacred. ... The sphere of sexuality becomes the zone of the sacred, where the world of work enters into decomposition, in the transports of eroticism. (149)

This is where eroticism leads us when we follow Bataille's logic of transgression: we fall into the sacred realm, and as such eroticism embraces the logic of sacredness. Transgression of seriousness is a sacrifice of the former, and it liberates forces that are hidden in the crystallized authoritative and meaningful faces. Eros is a desire for what

2 “'Milk is for the pussy, isn't it?' said Simone. 'Do you dare me to sit in the saucer?' ... The day was extremely hot. Simone put the saucer on a small bench, planted herself before me, and, with her eyes fixed on me, she sat down without my being able to see her burning buttocks under the skirt, dipping into cool milk. The blood shot to my head, and I stood before her awhile, immobile and trembling, as she eyed my stiff cock bulging in my trousers. Then I lay down at her feet without her stirring, and for the first time, I saw her 'pink and dark' flesh cooling in the white milk. We remained motionless, both of us equally overwhelmed...." (Bataille, Story 10) 
lies beyond the limits of discontinuous beings, and this beyond corresponds with what we call the sacred. The final step we need to take on Bataille's philosophy of eroticism is the analysis of what it means to be a saint in Bataillean terms - of what it means to be sovereign.

\section{Holiness and Sovereignty}

If the final step in our analysis of eroticism leads into an exploration of the notion of sacredness and holiness, it is because the place where erotic desires and actions take us lies within the same realm of existence. Eroticism is the breakthrough of continuous existence in the seriousness of the discontinuous one, and the sacred is the continuous realm, i.e. a realm of violence and eternity. Continuous existence is immortal, in the sense that it cannot die: it is a flux of energies circling around the world, and in that sense this flux never ends. The particular beings that are part of this continuous cycle are indeed dying, but their death takes part into the whole cycle. The death of the fawn is also the growth of the wolf. What death reveals is the violence of continuous existence, and it is only possible through the end of discontinuous existence, as the violence of the sea can only be truly experienced in the shattering of the boat on which the mariner stands. "Blindfolded, we refuse to see that only death guarantees the fresh upsurging without which life would be blind. We refuse to see that life is the trap set for the balanced order, that life is nothing but instability and disequilibrium. Life is a swelling tumult continuously on the verge of explosion." (Bataille, Erotism 59) Eroticism has a sense of death, because it makes us experience continuity through the death of our selfhood, through an experience of what is beyond the restricted vision of the restrained economy.

Sacredness and holiness partake in the same logic: in the sacred ritual, what happens is that the selfhood dies to meet the divine, i.e. the violent and exuberant energy that is considered life. God is love and God is life; and in the sacred texts of Judeo-Christian religions, what appears most often is the fact that the believer should abandon selfishness and embrace an openness to the glory of the divine. This, however, is still, according to Bataille, within the logic of seriousness and discontinuity, since God becomes the One discontinuous entity that masters the world, and the believer desires salvation for her own discontinuous soul. Without delving too much in these problems that are beyond the purposes of this paper, one must understand that the problem of religion is the rational aspect of it, i.e. the concentration of exuberance into stable divine entities that master the movement of the elements. Religion coincides with the dream of a pure rational principle that orders the world. What eroticism and sacredness have in common is not the belief in salvation or in the immortality of the soul, but the experience of the continuity of the world 
as a manifestation of violent and exuberant energies. "For every thing that lives is Holy" (Blake 45). This is the vision that is associated with mysticism, and as such mysticism and eroticism share a similar structure: in the vision of objects that are part of the discontinuous existence, the mystic and the erotic person see a gate towards continuous existence.

Mysticism reveals the divine in a negative way: through the negative theology, it is possible for the mystic to perceive holiness in the absence of objects. God, in that sense, is a presence that is similar to an absence: it is the continuity without discontinuity; being without any distinction, pure exuberance and movement. "Nothingness: the beyond of limited being. Strickly speaking, nothingness is what limited being isn't. You could say it's an absence, an absence of limit. Taken from another point of view: nothingness is what limited being desires, desire having for its object something that isn't doing the desiring." (Bataille, Guilty 157) Mysticism is thus deeply erotic, since the desire is not a desire of possession nor a desire to give, but a desire to be lost in what lies beyond one's limited being. The great mystics embrace what they call the night of knowledge, and often they will talk about the divine in a way that lies beyond language. In fact, their relation to God or gods is one that lies in a pure experience of continuous existence, a rapture that takes them beyond any possible language or rational explanation. Dante's final Canto in Paradiso is a beautiful account of that experience: God is an absence of objects, an absence of sense and a pure movement of energies that silences forever the possibility of describing Him. The experience of the sacred, the experience of the continuous existence that is the truth of religious life, is thus to be understood under the logic of Eros. "There is the beauty the Platonic eros contemplates, that eros that seeks immortal forms. ... The eros that chases after this kind of beauty is pursuing visions of immortality." (Lingis, Dangerous 143-4) Even in the Platonic sense, what is sought by Eros is immortality, and such a thing is only possible through the absence of material objects. The ladder of Eros, in Symposium, follows that logic: if the lover loves at first the beautiful objects, it is only to love, in the end, the eternal forms of these objects. Sacrificing the unique (isolated and limited) beauty to unleash what cannot die. Erotic love, however, is still subsumed under a vision of work, in the sense that what is immortal are forms that are perfect and stable - eternal in the sense that their crystallized perfect forms cannot die. Once more the dream of perceiving the world under pure rational principles.

The difference between eroticism and mysticism lies in the fact that where the latter seeks in the absence of objects the presence of the divine - of this entity that masters the elements, eroticism seeks the absence properly - the absence of sense. Mysticism finds sense in the night of reason, where eroticism experiences the absurdity of chance. The unique person in front of us, the uniqueness of the lover and the mortality 
of this lover opens up the possibility of seeing continuous existence. In the transgression of this unique person, in the transgression this person that is a chance, what is revealed is the truth of existence: the impossibility to make sense of our own existence, since we are all part of this exuberant movement of energies. In the erotic moment, what is sacrificed is the apparent necessity of our selfhood. In the transgression of selfhood, the chance that rules the world appears, and there is no god, no destiny, no fate, but only this impossible moment with this impossible person. When we quoted earlier Bataille saying that what we need from our lover is that she becomes the victim of the impossible, this is exactly it: we need to discover in the erotic love for our lover the impossibility of serious existence and of stability. In the melting away of seriousness and stability, what is revealed is the impossibility of an answer for our existence, because in this exuberant continuous existence, only chance rules.

This is what Bataille calls sovereignty, and what he calls sanctity. In tension with his own thought, it appears to be a form of salvation-on that is experience through an experience of evil. This is probably the biggest tension at play in Bataille's work: the line between the saint, the mystic and the erotic is very thin. Does Bataille really escape calculative reason by changing from a restrained to a general perspective? Is not sovereignty through evil a distorted form of salvation? If Bataille claims that the true erotic and sovereign experience depends on a chance-almost an experience of evil "grace"-it seems hard to conciliate with his appeal to transgression and numerous attempts to create, throughout his personal life, ritualistic secret societies. This is a problem left unsolved by Bataille - and it could be the task of those who read him to explore this issue of chance, that takes all the place in very aporetic works, such as $O n$ Nietzsche or Guilty.

The saint lives above the contingencies of the world, and consider each thing holy, since each thing is a manifestation of life and also a product of chance. "The autonomy - sovereignty - of man is linked to the fact of his being a question with no answer." (Bataille, Guilty 133) Embracing immanence, the saint will live in the world above the rules and will defy rational and limited possibilities. Death of subjectivity and objectivity; immanence of the creator that plays with the energies of the world, knowing that life is a play of forces and chances: only with the innocence of the child can we truly embrace this reality. Lack of seriousness and deep love for the world; desire of what lies beyond our limits as limited being; an embrace of the energies of life. The saint and the sovereign one are both above the rules and contingencies, because they do not live only in the discontinuous world: their task is to bring continuity in the discontinuous world, to do "miracles," i.e. to break the apparent order of things - even to transgress the apparent moral order. Opening up the world as a plane of immanence, and thus refusing to see 
things as crystallized, but always as fluid and immanent. Sovereignty as the state of innocence, in which the laughter of the child makes the world transparent and holy.

\section{Conclusion: Eros as an Experience of Existence}

Eros - or erotic love - is the gate towards sovereignty, because it is a gate towards continuous existence. The embrace of the flux of energies, of exuberant forces that cannot be totally controlled or subsumed under rational and moral principles, is the truth of eroticism. The truth of Eros is the secret, the mute and evil rumble of chaotic existence. Lovers meet at night under a tree in a forest, because that is the secret of love: the secretive movement, that can never stop. It is the movement of expenditure without a purpose other than existing as an $u s$. Loving like a wave loves another one, loving as in a dream that will end, but that is unique, because it is mine-and yours, and ours. Being secret, always moving. We are a secret — not because nobody knows, but because nobody can be part of our movement, of our deep experience of the world. That is how we started too: as secret lovers, partner in crime. Complicité, complicity: intimacy in something that must remain secret.

Conceived under this logic, what the sovereign one sees is exactly what the saint seeks to show: the secret of the world, the fact that everything is divine and immanent. Being secretive is going against the rules, going against the determined limits that tells one what to do or not to do. Playing with serious figures and forms of authority, Eros creates a space in which things are secretive, because they cannot be voiced out loud. In Bataille's Story of the Eye, children are the protagonists, and their erotic relationship unfolds through secrets and secretive actions. Hidden, or alone: never in public, and more than anything else, never with the thought of utility or satisfaction. A mere game that goes nowhere, but that can only accept players sharing the secretive life of the three children. When they are caught, parents are horrified, because that is also part of what it means to be secretive: horrifying figures of authority and seriousness.

Being erotic - embracing erotic love-does not mean being in a sexual intimacy with someone: it means being in a state of complicity that brings both lovers out of the realm of seriousness. It brings them back to state of immanence, where what is disclosed is the possibility of creating with the energies of life. The secret is a disturbance of stable life, because it must always move. As we saw, it means that it is living in the continuous existence, and as such it must follow the movement of life. Eros creates the possibility for fluidity: it is the desire of what lies within the limited self. When we said that erotic desire is a desire of lies beyond the limits, we meant that it is a desire of what lies beyond limited entities. 
"Beyond," not in an external sense, but in an intensive sense. What lies beyond limitations is exuberant energies, and this is always within limited beings. What lies beyond the limits is existence in its violence and nonrational aspect: it is the night in which we must immerse ourselves to feel part of the world. It is the ecstasy of the saint that feels the divine within her. It is the sovereign feeling when a lover gazes in his lover's eyes.

In that sense, the secret, the experience of life through Eros is an experience of violence and exuberance that takes us away from our selfhoods. It is something transgressive, but in this transgression what is sought is not satisfaction, but immanence. A phenomenology of Eros, then, would have to study the logic of transgression in its relation with immanence. It would look not at a history of sexuality, but at the history of taboos and their ultimate breaking apart. It would study the sacred aspect of different societies, and how figures of authority took control of sacredness to create an institution - a set of dogmas that are limiting the scope of the sacred. Ultimately, what this study would show is the movement of secret societies and how the secretive aspect of eroticism corresponds to the immanence of life.

Bataille's study of eroticism creates the possibility to see the desire of what lies beyond not under transcendental or external terms, but as a desire of letting the exuberance of life shining forth through the fall of seriousness. In that sense, Bataille's Eros is closer to Spinoza's conatus or Nietzsche's will to power: it is a desire to be. Eros as the desire of pure existence, and not as the experience of the ineffable.

Eroticism thus becomes not only an important aspect of human existence, but the possibility of a sovereign existence that would escape the contingencies created by the logic of work. It becomes the possibility for a continuous relationship with other human beings and the world. Eros is not pure immanence, but the desire to unleash immanence. Erotic is the gaze of the loved one, the caress of a lover, and the laughter of a child: erotic because they unleash forces that melt away our selfhood.

\section{Works Cited}

BAtAille, Georges. Le Coupable. Paris: Gallimard, 1961.

—. Erotism. Tr. Mary Dalwood. San Fransisco: City Lights Books, 1986.

—. Guilty. Tr. Bruce Boone. Venice (CA): The Lapis Press, 1988.

—. On Nietzsche, Tr. Bruce Boone. New York: Paragon House, 1994. 
-. Story of the Eye. Tr. Joachim Neugroschel. Toronto: Penguin Modern Classics, 2014.

Blake, William. The Complete Poetry \& Prose of William Blake. Ed. David V. Erdman. New York: Anchor Books, 1988.

Deleuze, Gilles, and Guattari, Félix. Milles Plateaux. Paris: Minuit, 1980.

FREUD, Sigmund. Three Essays on the Theory of Sexuality, The 1905 Edition. Ed. Philippe Van Haute \& Herman Westerink, Tr. Ulrike Kistner. New York: Verso Books, 2016.

Hegel, G. W. F. Phenomenology of Spirit. Trans. A. V. Miller. New York: Oxford University Press, 1977.

LingIS, Alphonso. Dangerous Emotions. San Fransisco: University of California Press, 2000.

-. Violence and Splendor. Evanston (IL): Northwestern University Press, 2011. 